\title{
Self-Image Improvement and Iranian EFL Learners' Oral Performance: Effects on Complexity, Accuracy, and Fluency
}

\author{
Zahra Alimorad, Shiva Yazdani \\ Shiraz University \\ Correspondence concerning this article should be addressed to Dr. Zahra Alimorad, Shiraz University, \\ Eram Square, Shiraz, Iran, E-mail: zahra.alimorad@shirazu.ac.ir
}

\begin{abstract}
The present study investigated the effects of self-image improvement on the quality of Iranian EFL learners' oral production. To this aim, 30 lower-intermediate university students were randomly divided into an experimental (EG) and control (CG) group. The main focus for both groups was enhancing the students' oral performance, however only the EG received the treatment via self-image improving techniques. Their self-image was measured with the aid of the Offer Self-Image Questionnaire (OSIQ) and their oral performance was examined using two parallel IELTS speaking tests before and after the treatment. It was found that by receiving self-image training, the participants' self-image improved, which led to a parallel improvement in their speaking skill. More specifically, the EG improved significantly in oral complexity and two components of oral fluency, mean length of run (MLR) and speech rate A (SRA). However, regarding oral accuracy and speech rate $B(S R B)$, no significant difference was observed between the two groups.
\end{abstract}

Keywords: accuracy, complexity, fluency, Iranian EFL learners, oral performance, self-image, quality

\section{Introduction}

The remarkable role of English is ever growing; never has there been a language so widely spoken as English (Crystal, 2003). Globalization, the development of communicative language teaching, and national and international academic demands are among the many reasons that have led English to become an international language with a prominent role in human lives (Knapp, 2015).

The rapid growth of this global trend coupled with the need for achieving proficiency in oral English ability has led to some scholars in the field focus on discovering the best ways to help improve students' ability to communicate in English (Richard, 2008). To date, psychological factors have received a lot of attention by researchers (Juhana, 2012) due to their seemingly indisputable role in determining improvements in second/ foreign language (S/FL) learners' oral proficiency (Haidara, 2014). Researchers have pointed to the relationship between and the effects of a number of these psychological constructs and the level of S/FL oral proficiency. To put it more clearly, studies have been done on the effects of or the relationship between English oral proficiency and self-confidence (Gurler, 2015; Juhana, 2012), learners' attitudes toward English (Norton \& Toohey, 2001; Zeinivand, Azizifar, \& Gowhary, 2015), self-esteem (Ahour \& Hassanzadeh, 2015; Devi \& Qiqiehi, 2016; Koosha, Ketabi, \& Kassaian, 2011), anxiety (Mai, 2011; Woodrow, 2006), motivation (Ihsan, 2016; Juhana, 2012), shyness (Al Nakhalah, 2016; Ostovar, Safaee, \& Sobhanifar, 2015), fear of making mistakes (Sato, 2003), personality types, introversion /extroversion (Mai, 2011; Meihua, 2012), and self-efficacy (Khatib \& Maarof, 2015; Liu, 2013).

To communicate successfully in English is to possess a fair level of oral proficiency which, as Omaggio (1986) asserts, equals accurate and functional verbal communication in the target language. Successful communication in English requires learners to produce fluent and accurate language of an appropriate level of structural complexity. Many L2 practitioners and SLA (Second Language Acquisition) researchers hold that S/FL oral proficiency consists of three principal components: complexity, accuracy, and fluency, or CAF (Ellis, 2008; Norris \& Ortega, 2009). 
Generally, fluency is defined as the ability to produce speech with ease, at a normal rate, without hesitations and unnecessary pausing, manifested in continuous, smooth, and native-like speech (De Jong, 2012; Ellis \& Barkhuizen, 2005). As another component of the CAF triad, accuracy (or correctness) is regarded as the most internally consistent one and it refers to the correct and error-free use of language as well as the extent to which S/FL performance deviates from target language norms or sticks to target-like language use (Housen \& Kuiken, 2009). Complexity refers to both linguistic and cognitive complexity in SLA literature. Cognitive complexity is the relative difficulty with which language elements are processed during S/FL performance, while linguistic complexity refers to formal and linguistic properties of S/FL elements (Housen \& Kuiken, 2009) interpreted as varied, complex, rich, elaborated, and sophisticated target language produced by the learner (Ellis \& Barkhuizen, 2005).

Researchers recommend different methods for measuring each of these components. Accuracy can be measured in either a specific or a general manner (Ellis \& Barkhuizen, 2005). The former deals with the accurate production of a specific form (suitable for focused tasks) while the latter is inclusive of the learner's overall accuracy (Iwashita, 2010), which is sufficiently informative (Ahmadian \& Tavakoli, 2011) and recommended over the specific one (Ellis \& Barkhuizen, 2005). According to Delaney (2012), general accuracy can be measured as the ratio of error-free clauses to the total number of clauses.

SLA researchers measure complexity according to syntactic and lexical complexity (Norris \& Ortega, 2009). Lexical complexity is measured by D, a sophisticated TTR (the type-token ratio) measure that adjusts for the length of text (McKee, Malvern, \& Richards, 2000) and can be measured by CLAN software (Li, Chen, \& Sun, 2015). Syntactic complexity is also measured as the ratio of total clauses to AS-units (Analysis of Speech Unit: a main clause and any attached subordinate clauses or sub-clausal units) (Delaney, 2012).

Fluency is measured as the mean length of run (MLR) and speech rate, which is the most common and trusted way according to previous studies (e.g., Li et al., 2015, Skehan \& Foster, 2005). According to Li et al. (2015), MLR is measured by the mean number of syllables produced in utterances between pauses with the standard of 0.28 seconds being considered the cutoff point of a pause. Speech rate includes speech rate A (SRA), which is the ratio of syllables to the complete time it takes to produce them, and speech rate B (SRB), which is similar to SRA; however, syllables, words, phrases, or clauses that are repeated, reformulated, or replaced are not considered.

\section{Literature Review}

The available literature is replete with various psychological constructs beginning with self, such as selfconfidence, self-concept, self-efficacy, and self-esteem from which self-image can conspicuously be distinguished. Self-image is a mental blueprint and a cognitive representation of self, personality, mental functioning, social attitudes and a base upon which one's personality, behaviors, and life circumstances are built (Di Blasi et al., 2015; Maltz, 1960; Proctor, 2002) which is created from an individual's beliefs about oneself (Maltz, 1960; Proctor, 2002); beliefs that have unconsciously been formed from past experiences of success, failure, happiness, and humiliation, especially in childhood (Maltz, 1960; McMullen, 2013; Proctor, 2002).

Self-image is thus a multidimensional construct manifested through performing in various social settings and psychological functioning. Therefore, this construct should be measured as a multifaceted concept as well (Offer, Ostrov, Howard, \& Atkinson, 1988). Offer et al.'s (1988) conceptualization of self-image encompasses five main selves: 1) Psychological self which comprises concerns, feelings, wishes, and fantasies 2) Social Self which revolves around the individual's social life 3) Sexual self and an individual's sexual drives 4) Familial self and the feelings and attitudes individuals have toward their families, and 5) Coping self and how individuals cope with their world. Although each self shows a different aspect of self-image, together, they provide a thorough depiction of one's self-image (Offer et al., 1988).

Once formed, self-image acts as an inner thermostat directly controlling one's behaviors, actions, feelings, abilities, life circumstances, goals, end results, and even others' reactions to oneself. Ideas that are inconsistent 
with self-image would be rejected, not believed and not acted on. While human beings proceed to act upon their self-image without questioning its validity, no one would be able to outperform or act despite it. Even if one manages to briefly escape, they will be snapped back quickly (Maltz, 1960; Proctor, 2002) just as the person with a failed self-image will find a way to fail in spite of all their conscious efforts, willpower, and good intentions (Hirsch, Meynen \& Clark, 2004; Maltz, 1960; Proctor, 2002). Nonetheless, self-image is a dynamic construct (Offer et al., 1988) that, if understood and managed, can be changed and improved to suit life purposes, and become the key to living without limit (Maltz, 1960; Proctor, 2002) since "it controls mind, just as surely as mind controls heartbeats" (Proctor, 2002, p. 7).

As an example of the early studies on the relationship between self-image and educational performance, Sopis (1965) investigated the self-image of students with reading problems. She hypothesized that students' poor performance was the result of their inaccurate definition of themselves. To examine this, she placed 240 students from grades two, three, four, and five in some reading sessions. Participants defined themselves using the Colvin Silhouette test as having high, average, or low self-images in reading. The results indicated a direct correlation between pupils' performance and their level of self-image.

In another study, Glazier (1998) witnessed that students in remedial English writing courses suffered from poor self-image. They had been labeled failures before and those remedial courses were only second reminders. The researcher proposed six ways to help those disheartened students improve their self-image and English writing skills. Alleviating failure, freeing students from inhibitions, and giving students a sense of confidence and success were among the self-image improvement principles proposed and used by the researcher. As a result of implementing the proposed principles in writing courses at Western Illinois University, many students in those courses showed significant improvement. Later, their other writing instructors also reported that the students performed even better than many regular students. They were said to have become confident, handed in their papers without failure, prepared well-organized papers, come to classes motivated, become ready to learn, and taken criticism well because they believed they could improve; and the biggest change was said to be that of their attitudes about themselves.

Using a different approach, Lee and Oxford (2007) narrowed down the perspective and focused only on English learning self-image and its effects on students' English performance. More than 500 Korean students from both traditional and vocational schools participated in the study, and their self-image was assessed using the Background Information Questionnaire. The results showed that the vocational students' poor performance was the result of their impaired English-learning self-image.

Sandi-Urena and Gatlin (2013) also investigated the effects of self-image on academic achievement. They examined the association between the self-image of 24 laboratory graduate teacher assistants (GTAs) and their performance in the labs as laboratory instructors. Information on self-image and teaching styles were collected using interviews, memos, training artifacts, laboratory manuals, and syllabi. The findings showed that GTAs' performance was in accordance with their type of self-image.

Reviewing the related literature, the present researchers did not find any studies on self-image and academic performance for EFL learners and, in particular, their speaking performance. Therefore, to fill this gap, the present study can serve as a stepping stone for further studies on this under-researched area of enquiry.

Building upon the notion that the prime cause of success or failure is one's own self-image (Maltz, 1960; Proctor, 2002), and that many underachieving learners are simply the victims of their own negative self-image, this study aimed at helping English learners improve their oral proficiency through, first, improving their selfimage using psychological techniques. To this end, attempts were made to transform students' self-image into more realistic, positive, and success-oriented ones by employing scientific, and psychological techniques put forth by Maltz (1960). Considering the objectives, the present study was motivated by two research questions:

RQ1: Does Iranian EFL learners' self-image improve as a result of receiving self-image psychological training techniques?

RQ2: Is there any significant difference between the performance of students who received the self-image improvement techniques with those who did not in terms of (a) the accuracy of their oral production, (b) the complexity of their oral production, (c) the fluency of their oral production? 


\section{Methodology}

\section{Participants}

Thirty undergraduate university students agreed to participate in this study. To determine their proficiency level, Oxford's QPT (Quick Placement Test) was given to the students. All of the participants' (female $=20$, male $=10$ ) native language was Persian and their age ranged from 20 to 25 . To determine the effects of the treatment, they were randomly assigned into a control group ( $C G, N=15)$ and an experimental one $(E G, N=15)$. All of the participants in both groups were assured of the confidentiality of their identities throughout the study as well as in the report of its results.

\section{Instruments}

Two main instruments were used to collect the needed data. However, as mentioned above, since it was necessary to determine the proficiency level of the students in order to ensure that the two groups were homogeneous prior to the treatment, the QPT was used as a prerequisite for the experiment. This test consisted of two parts. Part One (questions 1-40) was taken by all candidates and was aimed at participants who were at or below an intermediate level. Part Two was geared towards more proficient participants and those who scored more than 35 on the first part of the test (Geranpayeh, 2003).

As one of the main instruments, two parallel IELTS speaking interviews were used as pre- and post-speaking tests. While ideally it would have been better to use the same measurement utilized in the pre-test (i.e., IELTS speaking Test 1) to examine students' progress in their speaking skills as the result of the experiment, the practice and memory effect bias could have not been avoided (Ary, Jacobs, Sorensen Irvin, \& Walker, 2019; Cliffordson, 2004; Geving, Webb, \& Davis, 2005; Hausknecht, Halpert, Di Paolo, \& Gerrard, 2007; Lievens, Buyse, \& Sackett, 2005). That is why two different, but parallel, IELTS speaking tests were utilized in this study. IELTS tests in general, and IELTS speaking test in particular, have a very structured nature and are of the same level of difficulty (Brown \& Hill, 2007). The tests were drawn from the book IELTS 11 (Appendix A). In this study, all of the participants in both the EG and CG participated in the oral interviews conducted at the beginning and end of the experiment by the second researcher under the direct supervision of the first researcher who was also the main supervisor of this study. The second researcher was a trained interviewer and conducted all the oral speaking tests herself.

The oral interviews were all recorded and transcribed in order to assess different components of CAF. In order to determine the inter-coder reliability of the oral speaking tests, the second researcher was trained by her supervisor to code the data. Then, a randomly selected sample of the data was given to another M.A. student who had already done the same coding for his M.A. thesis and was familiar with the procedures. The correlation between the two sets of coding was calculated and turned out to be $98 \%$, which was satisfactory for the purposes of the current study.

Moreover, the participants' level of self-image was assessed using an adapted version of the Offer Self-Image Questionnaire (OSIQ) originally developed by Daniel Offer and his colleagues in 1961. It was a 99-item inventory. Six items were omitted due to their being culturally inappropriate for the context of Iran. The questionnaire was then translated by the second researcher into Persian and after a back-translation by a graduate English student from the Department of Foreign Languages and Linguistics of Shiraz University, some items were modified. The final draft of the translated questionnaire was approved by an assistant professor of TEFL, who was an expert in the field, from the same department. Responses were elicited on a 6-point Likerttype scale form describes me very well to does not describe me at all. Based on the data from the 30 participants of the study, its Cronbach alpha reliability index was estimated using SPSS software and turned out to be 0.788 , which seemed acceptable for the purposes of the current study.

\section{Materials}

Maltz's (1960) worksheet was used as a self-improvement aid in this study. To help people improve their selfimage, in his book Zero Resistance Living, Maltz (1999) presents some psychological techniques in the form of a 12 -session worksheet. Each lesson in the worksheet is divided into two main parts. The first part contains an 
introduction to the lesson plus some inspirational anecdotes and scientific facts about human self-image and psychological behavior while the second part is devoted to exercises for each lesson (See a sample of Lesson 1 of this worksheet as an example in Appendix B).

\section{Treatment}

Given that the students were undergraduate students of diverse majors, it was envisaged that they were busy taking different classes. Therefore, to avoid interfering with their university schedule, the experiment was conducted in the evenings. During the experimental treatment, the second researcher orally presented the first part of each self-image improvement lesson to the participants in the EG in their native language. This part usually lasted between ten to fifteen minutes. The rationale behind using their native language during selfimage improvement training periods was to avoid providing EG students with extra exposure to English as compared with the CG participants. PowerPoint presentations were used when needed. The next part of the lesson, which went on for about twenty minutes (the recommended time span proposed by Maltz, 1960), and which consisted of self-image improvement exercises, was translated into Persian and handed to the participants each session. Once the self-image improvement part of the EG's class was over (about the first thirty minutes of each session), the class proceeded with English speaking activities that were identical in both the EG and CG. The entire experiment lasted for 12 sessions (as recommended by Maltz, 1960), three days a week for two weeks. This study schedule was adopted in order to avoid interrupting the participants' university schedule and their impending final exams. In order to determine the integrity of the treatment, a professor of psychology at Shiraz University agreed to help the researchers in this regard. He was consulted with prior to the experiment; and, during repeated and continuous sessions, he passed on the required therapeutic skills to the second researcher who was responsible for carrying out the self-image treatments. The self-image treatment sessions were regularly reported to that professor so that adherence to the manual would be checked as well. Therefore, benefiting from the direct supervision of the psychology professor and by closely following his advice and recommendations, the two researchers of this study were able to maintain the adherence/ competence protocol (Mcleod et al., 2017; Waltz, Addis, Koerner, \& Jacobson, 1993) regarding the psychological part of their experiment (i.e., the self-image improving treatment).

As mentioned above, after presenting the self-image improving techniques in the EG, their class proceeded with English speaking activities that were identical to those of the CG. That is, to improve their Englishspeaking skill, the same procedure was followed in both the EG and CG. A point that must be borne in mind is that since the participants' command of English was at a low-intermediate level, holding the class as a mere chat class was not an option. For this reason, some parts of the two books Top Notch Fundamental B and New Interchange 2 were selected to be taught to the learners so that the participants could learn to give speeches on various topics. Speaking topics were elicited from the New Interchange book. Selected topics for speaking from the New Interchange book were introduced, proper and related structures were explained, and then related vocabulary for each topic was taught.

The participants were encouraged to hold discussions with their peers rather than simply offer answers to the instructor. Moreover, since learners had little to no exposure to authentic spoken English outside the classroom, they were asked to watch two seasons of the four-season Disney original teen series Wizards of Waverly Place each week. They were then asked to give oral and written summaries and to write down all the new words and expressions they heard and understood. Occasionally, some parts of the series were played in the class as a way to teach the participants new vocabulary and everyday expressions. Furthermore, to meet the purpose of the experiment, the EG was asked to watch the aforementioned series and then, as their self-image homework practice, imagine themselves being able to speak just like those native speakers they had watched and heard.

\section{Data Collection and Analysis Procedures}

The selected sample was randomly assigned to an EG and a CG. The OSIQ was given to the participants in both groups at both the outset and the end of the study to assess any improvements in their self-image. It is worth mentioning that no time limit was defined for the completion of the questionnaires. Likewise, two IELTS speaking tests with similar topics were selected as parallel tests for the pre- and post-tests in the study. Participants' responses to the oral IELTS interviews were recorded and transcribed and the quality of their productions was measured by tapping its components; namely, accuracy, fluency, and complexity. Accuracy 
was measured as the ratio of error-free clauses to the total number of clauses (Delaney, 2012). Following Foster and Skehan's (1996) definition, an error-free clause is "a clause in which there is no error in syntax, morphology, or word order. Errors in lexis were counted when the word used was incontrovertibly wrong. In cases of fine decisions of appropriacy, no error was recorded" (p. 310).

Two of the most commonly used fluency measures were used in this study: MLR and speech rate (Li et al., 2015). MLR was measured by counting the number of syllables produced between pauses lasting more than 0.28 seconds. Speech rate was also divided into SRA and SRB. The former was measured as the ratio of syllables to the time it took the participant to do the task, and for measuring the latter, the same procedure was followed except that syllables, words, phrases, or clauses that were repeated, reformulated, or replaced were not considered (Li et al., 2015).

Complexity was measured in terms of the two categories of syntactic complexity and lexical diversity. Syntactic complexity was measured as the ratio of clauses per AS-unit. Lexical complexity was also measured by calculating the D value, which is considered a more reliable measure than type-token ratio (Malvern \& Richards, 2002) using CLAN software (Delaney, 2012; Li et al., 2015). To analyze the data, the experimental treatment was considered as the independent variable and values were assigned to the participants according to their presence in either the EG or CG. More specifically, to uncover any differences between these two groups in terms of their improvements regarding oral performance accuracy and given that oral accuracy had only one aspect (i.e., the ratio of error-free clauses to the total number of clauses), which was considered as the dependent variable, an independent samples t-test was run ${ }^{1}$. Moreover, since oral complexity was measured by analyzing the two components of lexical diversity and syntactic complexity, that is, there were two dependent variables, a MANOVA test was run $^{2}$. Additionally, as oral fluency was assessed by calculating its three components (i.e., MLR, SRA, and SRB), another MANOVA test was conducted ${ }^{3}$. Before embarking on MANOVA, its assumptions needed to be checked ${ }^{4}$. To check multivariate normality, Mahalanobis Distances was also calculated. Finally, the homogeneity of variance-covariance matrices was examined by considering Box's M Test of Equality of Covariance Matrices and Levene's Test of Equality of Error Variances was used to make sure that the assumption of equality of variance for each variable was not violated ${ }^{5}$. All of the above-mentioned calculations were done using SPSS software.

\section{Results}

To ensure the homogeneity of the two groups prior to the experiment, two independent samples t-tests and two MANOVAs were run on the scores attained from the first administration of the OSIQ as well as the participants' pre-test oral scores. The results indicated that the two groups were homogenous in terms of accuracy, complexity, and fluency as well as their self-image at the outset of the study.

\section{Effect of the Psychological Training Techniques on Learners' Self-Image}

To examine the effectiveness of self-image psychological training, independent samples t-tests were run on data attained from pre- and post-test administration of the OSIQ in both the EG and CG. These results are displayed in Table 1 .

\section{Table 1}

Independent Samples t-test for Self-image Pre- and Post-test Results

\begin{tabular}{|c|c|c|c|c|c|c|c|c|c|c|c|c|c|c|}
\hline & \multicolumn{6}{|c|}{ Pre-test } & \multicolumn{7}{|c|}{ Post-test } & \multirow[b]{2}{*}{ Cohen's d } \\
\hline & $\mathbf{N}$ & $\mathbf{M}$ & SD & f & $\mathbf{t}$ & Sig. & $\mathbf{N}$ & M & SD & f & $\mathbf{t}$ & Sig. & Effect size & \\
\hline EG & 15 & 311.80 & 18.27 & 0.02 & 1.21 & .23 & 15 & 316.33 & 12.75 & .08 & 1.26 & .000 & .58 & 1.5 \\
\hline CG & 15 & 302.38 & 22.58 & & & & 15 & 292.13 & 15.54 & & & & & \\
\hline
\end{tabular}

${ }^{1}$ Pallant, J. (2011). SPSS Survival manual: A step by step guide to data analysis using SPSS for windows. McGrew Hill.

${ }^{2}$ Ibid.

${ }^{3}$ Ibid.

${ }^{4}$ Ibid.

${ }^{5}$ Ibid. 
As depicted in Table 1, the results of the independent samples t-tests revealed that although the two groups had been homogeneous in terms of their self-image when the study commenced ( $p=.23>0.05$ ), a significant difference in the self-image level of the $\mathrm{EG}(\mathrm{M}=316.3, \mathrm{SD}=12.7)$ and $\mathrm{CG}(\mathrm{M}=292.13, \mathrm{SD}=15.5 ; \mathrm{t}(28)=1.26$, $\mathrm{p}=0.00<0.05$, two-tailed) was observed after the treatment. Moreover, by measuring Cohen's $d$ value $(\mathrm{d}=1.5)$, it was further confirmed that the changes between the two groups regarding improvements in terms of the quality of their self-image was rather meaningful (Plonsky \& Oswald, 2014).

\section{Comparing EG and CG oral English accuracy}

In order to determine whether the two groups' level of oral accuracy underwent any changes during the course of the experiment, two paired samples t-tests were run and the results are provided in Tables 2 and 3.

Table 2

Paired Samples Statistics

\begin{tabular}{lllccc}
\hline & & Mean & N & SD & Std. Error Mean \\
\hline Pair 1 (EG) & Pretest & .2993 & 15 & .10437 & .02695 \\
& Posttest & .3960 & 15 & .11096 & .02865 \\
\hline \multirow{2}{*}{ Pair 2 (CG) } & Pretest & .3020 & 15 & .06570 & .01696 \\
& Posttest & .3613 & 15 & .07337 & .01895 \\
\hline
\end{tabular}

Table 3

Paired Samples Test

\begin{tabular}{|c|c|c|c|c|c|c|c|c|c|}
\hline & \multirow{3}{*}{ Mean } & \multicolumn{5}{|c|}{ Paired Differences } & \multirow{3}{*}{$\mathbf{t}$} & \multirow{3}{*}{ df } & \multirow{3}{*}{$\begin{array}{c}\text { Sig. } \\
\text { (2-tailed) }\end{array}$} \\
\hline & & \multirow{2}{*}{ SD } & \multirow{2}{*}{$\begin{array}{l}\text { Std. Error } \\
\text { Mean }\end{array}$} & \multicolumn{3}{|c|}{ 95\% Confidence Interval of the Difference } & & & \\
\hline & & & & Lower & Upper & & & & \\
\hline Pair 1 & Pretest - Posttest (EG) & -.09667 & .08723 & .02252 & -.14497 & -.04836 & -4.292 & 14 & .001 \\
\hline Pair 2 & Pretest-Posttest (CG) & -.05933 & .02764 & .00714 & -.07464 & -.04403 & -8.315 & 14 & .000 \\
\hline
\end{tabular}

As revealed in these two tables, there was a statistically significant increase in their scores from pre-test (M=.29, $\mathrm{SD}=.10)$ to post-test $(\mathrm{M}=.39, \mathrm{SD}=.11), \mathrm{t}(14)=-4.29, \mathrm{p}<.0005$ (two-tailed) for the EG and a parallel increase in the scores from pre-test $(\mathrm{M}=.30, \mathrm{SD}=.06)$ to post-test $(\mathrm{M}=.36, \mathrm{SD}=.07), \mathrm{t}(14)=-8.31, \mathrm{p}<.0005$ (two-tailed) for the CG. The mean increase in accuracy scores of the EG and CG was -.09 and -.05 with a $95 \%$ confidence interval ranging from -.14 to -.04 and -.07 to -.04 , respectively. Ethically speaking, we did expect that learning would happen in both groups after a period of instruction but what we were more concerned about was the effect of the treatment on the accuracy scores of the EG compared to the CG, which was investigated using an independent samples t-test.

Table 4

Independent Samples t-test for Oral English Accuracy Pre- and Post-test Results

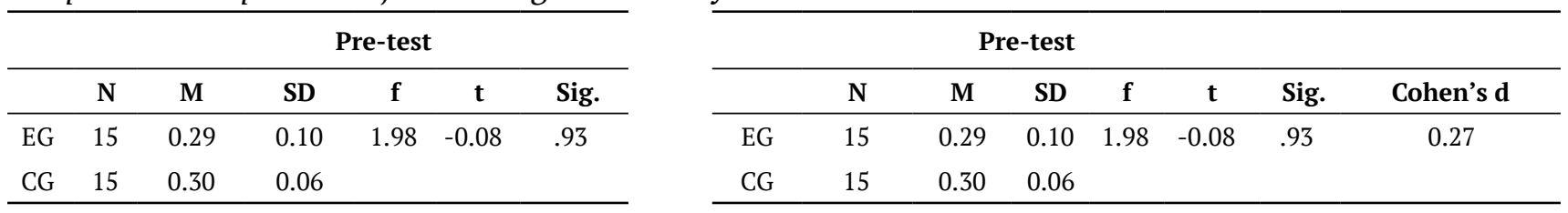

Table 4 indicates that in terms of the accuracy of their oral production, no statistically significant difference was seen after the implementation of the treatment in the $\mathrm{EG}(\mathrm{M}=0.39, \mathrm{SD}=0.11)$ and $\mathrm{CG}(\mathrm{M}=0.36, \mathrm{SD}=0.07$; $\mathrm{t}$ $(28)=1.009, p=.32>0.05$, two-tailed $)$. Cohen's $d$ value $(d=0.27)$ further indicated that the difference between the two groups in terms of their oral accuracy was not meaningful (Plonsky \& Oswald, 2014). To answer the first part of the second research question, it must be pointed out that although oral accuracy in the EG improved (M pre-test $=0.29$, M post-test $=0.39$ ), this improvement was not significantly different from that of the CG (M pre-test $=0.30$, $\mathrm{M}$ post-test $=0.36$ ). 


\section{Comparing EG and CG Oral English Complexity}

Prior to running MANOVA, its assumptions had to be checked ${ }^{6}$ using SPSS. It was found that all assumptions were met (Mahalanobis distance value $=4.38<13.82$; Box's test $=0.916>0.001$; Levene's test $=0.899,0.647>0.05$ ), which let the researchers proceed to run the MANOVA test itself. Table 5 shows the output of this test.

Table 5

Multivariate Tests for Oral English Complexity

\begin{tabular}{lcccccc}
\hline \multicolumn{1}{c}{ Effect } & Value & F & Hypothesis df & Error df & Sig. & Partial Eta Squared \\
\hline Wilks' Lambda (Pre-test) & .830 & $2.769^{\mathrm{a}}$ & 2.000 & 27.000 & .081 & .170 \\
Wilks' Lambda (Post-test) & .567 & $10.316^{\mathrm{b}}$ & 2.000 & 27.000 & .000 & .433 \\
\hline
\end{tabular}

As Table 5 depicts, despite being homogeneous in terms of their oral English complexity at the outset of the study, $\mathrm{F}(2,27)=2.769, \mathrm{p}=.081>0.05$, Wilks' Lambda $=.830$, eta squared $=.170$, a statistically significant difference was found between the EG and CG with respect to the effect of the treatment on both dependent variables of oral complexity, $\mathrm{F}(2,27)=10.31, \mathrm{p}=.000<0.05$, Wilks' Lambda $=0.56$, eta squared $=0.43$. To examine the main effect of the treatment on the degree of change for each dependent variable, independent samples t-tests were run on data from the pre- and post-interviews for both the EG and CG. These results are displayed in Table 6.

Table 6

Independent Samples t-test for Oral Complexity Pre- and Post-test Data

\begin{tabular}{cccc}
\hline \multicolumn{3}{c}{ Pre-test } \\
\hline & Groups & Mean & SD \\
\hline LC & EG & 56.57 & 4.05 \\
& CG & 51.18 & 7.74 \\
\hline \multirow{2}{*}{ SC } & EG & 1.12 & 0.09 \\
& CG & 1.11 & 0.7 \\
\hline
\end{tabular}

\begin{tabular}{ccccc}
\hline \multicolumn{4}{c}{ Post-test } & \multirow{2}{*}{ Cohen's d } \\
\cline { 1 - 4 } Mean & SD & Sig. & t & \\
\hline 72.00 & 7.80 & 0.001 & 3.89 & 1.46 \\
61.10 & 7.52 & & & \\
\hline 1.22 & 0.07 & 0.000 & 3.98 & 1.42 \\
1.12 & 0.07 & & & \\
\hline
\end{tabular}

The results in Table 6 show that participants' oral complexity in terms of lexical complexity in the EG (M= $72.00, \mathrm{SD}=7.80)$ and $\mathrm{CG}(\mathrm{M}=61.10, \mathrm{SD}=7.52 ; \mathrm{t}(28)=3.89, \mathrm{p}=0.001<0.05)$ was significantly different. Moreover, Cohen's $d$ value $(d=1.46)$ revealed that the difference between the two groups in terms of their lexical complexity was meaningful (Plonsky \& Oswald, 2014). In terms of syntactic complexity, a statistically significant difference was also seen between the $\mathrm{EG}(\mathrm{M}=1.22, \mathrm{SD}=0.07)$ and $\mathrm{CG}(\mathrm{M}=1.12, \mathrm{SD}=0.07 ; \mathrm{t}(28)=3.98$, $\mathrm{p}=.000<0.05)$. Measuring Cohen's $d$ value $(\mathrm{d}=1.42)$ further indicated that the changes between the EG and CG regarding their level of syntactic complexity was rather meaningful (Plonsky \& Oswald, 2014).

\section{Comparing the EG's and CG's oral English Fluency}

In this section, to overcome the problem of correlated observations, $p$-values less than .01 were considered statistically significant, as recommended by Stevens (2009). Furthermore, before conducting MANOVA, its assumptions were checked and all were met (Mahalanobis distance value $=10.94<16.27$; Box's test $=0.418>0.001$; Levene's test $=0.32,0.38,0.39>0.05$ ). Table 7 shows the output for these results.

Table 7

Multivariate Tests for Oral English Fluency

\begin{tabular}{lcccccc}
\hline \multicolumn{1}{c}{ Effect } & Value & F & Hypothesis df & Error df & Sig. & Partial Eta Squared \\
\hline Wilks' Lambda (Pre-test) & .972 & $.248^{\mathrm{a}}$ & 3.000 & 26.000 & .862 & .028 \\
Wilks' Lambda (Post-test) & .256 & $25.150^{\mathrm{b}}$ & 3.000 & 26.000 & .000 & .744 \\
\hline
\end{tabular}

As Table 7 shows, the two groups were homogeneous in terms of their oral English fluency before the treatment, $\mathrm{F}(3,26)=.248, \mathrm{p}=.862>0.01$, Wilks' Lambda $=.972$, eta squared $=.028$; however, a statistically significant difference was detected between the two groups' oral fluency, $F(3,26)=25.150, p=.000<0.01$, Wilks' Lambda $=0.256$, eta squared $=0.74$. To examine the effect of the treatment on each of the dependent variables of fluency separately,

\footnotetext{
${ }^{6}$ Pallant, J. (2011). SPSS Survival manual: A step by step guide to data analysis using SPSS for windows. McGrew Hill.
} 
as follow-up analyses, three independent samples t-tests were run on MLR, SRA, and SRB. These results are displayed in Table 8.

Table 8

Independent Samples t-test on Post-test Results of Oral English Fluency

\begin{tabular}{llccccc}
\hline & & Mean & SD & Sig. & t & Cohen's d \\
\hline MLR & EG & 3.53 & 0.74 & 0.000 & 4.30 & 1.81 \\
& CG & 2.48 & 0.58 & & & \\
\hline SRA & EG & 68.02 & 13.22 & 0.000 & 5.77 & 0.27 \\
& CG & 65.67 & 8.57 & & & \\
\hline SRB & EG & 74.70 & 11.10 & 0.569 & 5.77 & 2.62 \\
& CG & 54.56 & 7.66 & & & \\
\hline
\end{tabular}

As shown in Table 8, a statistically significant difference was found in terms of MLR and SRA scores $(p=.000<0.01)$. On the contrary, no statistically significant changes were seen in the scores of the EG $(M=74.70$, $\mathrm{SD}=11.10)$ and $\mathrm{CG}(\mathrm{M}=54.56, \mathrm{SD}=7.66 ; \mathrm{t}(28)=5.77, \mathrm{p}=0.569>0.1$, two-tailed) regarding $\mathrm{SRB}$. Moreover, and drawing on Plonsky and Oswald (2014), to supplement information from statistical significance tests, the "practical significance" (p. 879) of oral fluency measurement was addressed as well. As a result, Cohen's d value was measured for each oral fluency variable (i.e., MLR, SRA, and SRB), and interpreted based on Plonsky and Oswald's (2014) L2 specific benchmark proposed for interpreting practical significance in L2 studies; where a d value in the neighborhood of 0.40 is generally considered small, 0.70 medium, and 1.00 large. Therefore, and as shown in Table 8, practical significance was found in terms of MLR $(\mathrm{d}=1.81)$ and SRB $(\mathrm{d}=2.62)$. However, no practical significance was seen in the EG and CG regarding their SRA $(\mathrm{d}=0.27)$. In other words, and statistically speaking, the EG improved in terms of MLR and SRA. But regarding practical changes, the EG significantly progressed in terms of MLR and SRB but no practically significant improvement was observed in terms of SRA.

\section{Discussion}

As a result of the self-image treatments, and according to the findings, it can convincingly be argued that selfimage training techniques were conducive to developing stronger and better-formed self-images for the EG participants who received the treatment. Comparing the CG's mean score gained on the first administration of the OSIQ (M = 302.38, $\mathrm{SD}=22.58)$ and the second one $(\mathrm{M}=292.13, \mathrm{SD}=15.54)$, it would be safe to say that not only did the level of self-image in the CG not remain constant, but it diminished slightly, which is in line with Maltz's (1960) remark that overall, the unconscious mind (where self-image is located (Maltz, 1960)) tends to draw on negativities when overlooked rather than on positive thoughts and feelings. Therefore, a mindful approach towards self-image is highly recommended (Maltz, 1960, Proctor, 2002). Improvement in self-image as a result of receiving an intervention is in line with previous studies conducted by Hintikka et al. (2006) and Ryum, Vogel, Walderhaug, and Stiles (2015) in which participants'/patients' levels of self-image improved significantly, almost to that of a normal person, after undergoing the treatments.

As for changes in terms of learners' levels of oral accuracy, the findings enjoy the support of previous research that reported the rather slow development of accuracy over other oral production components like fluency due to the existence of the trade-off effect (Skehan, 2009). However, the same finding is not in line with those of Li et al. (2015) and Vercellotti (2015) who reported a rather concurrent change across all CAF components. Nevertheless, this finding may be justified on the grounds that the participants might have focused more on meaning and not form, and as Skehan (2009) suggested, a trade-off exists between fluency and accuracy. Thus, due to the shortage of memory to pay attention to both the accuracy and fluency of their oral production (Skehan, 2009), they were not able to achieve significant improvements in terms of oral accuracy within the time span of the experiment. The same finding, however, contradicts the results of Meisel, Clahsen, and Pienemann (1981) who reported the positive effects of learners' motivation, as another psychological construct, on reaching a high level of oral accuracy. 
To answer the second part of research question two, it can be argued that the findings showed a statistically significant difference between the performance of the EG and CG in terms of both lexical and syntactic complexities. Improvement in terms of oral complexity is in line with a number of previously conducted research projects on other psychological constructs. Li et al. (2015) reported improvement in complexity as a result of receiving speaking treatment. The results are also in line with Park and Lee's findings (2005) which showed that participants with high levels of self-confidence and low anxiety had stronger English oral proficiency in terms of ease of speech, interaction, delivery, and complex use of language. Nevertheless, to the best of the present researchers' knowledge, no study has examined the effects of self-image improvement on S/ FL learners' oral complexity. Therefore, this area of inquiry warrants further investigation to confirm or refute these findings.

With regard to the learners' oral fluency, the results indicated that the EG statistically improved in terms of MLR and SRA, but practically (Plonsky \& Oswald, 2014) only progressed in terms of MLR and SRB. One possible justification for the small $d$ value for SRA $(d=0.27)$ is that this research was conducted in a classroom context in contrast to the controlled environment of a laboratory where greater rigor and experimental control is feasible; hence higher d values (Cohan, 1988). Also, since the CG in this study was not a true control group but a comparison group (they received the traditional treatment), the effect size for SRA was not that large (Norris, 2012; Plonsky \& Oswald, 2014). The nature of the research must also be put in perspective when interpreting effect size values (Lipsey, 2009; Vacha-Haase \& Thompson, 2004). Therefore, the lower d value of oral accuracy $(\mathrm{d}=0.27)$ compared to the high $\mathrm{d}$ value of oral fluency (in general), can be due to the very existence of the trade-off between oral fluency and oral accuracy as first reported by Skehan (2009).

All that being said, it must be borne in mind that, at times, the minimal time, costs, and resources needed to implement a certain technique, despite its low effect size values, and considering the potential beneficial results of implementation, justify the interventions (Plonsky \& Oswald, 2014); as in the case of Lee and Huang (2008) and Alsadhan's (2011) study, which showed that implementing their input enhancement and noticing techniques proved to be useful in practice despite the initial low d values of .22 and .30. In this study, too, implementing self-image improvement techniques as a way to enhance the quality of English learners' oral fluency was cost effective and feasible. And considering the possible positive effects, it sounds fine to apply these techniques despite the low numerical $d$ values in the case of SRA ( $d=0.27)$, and /or oral accuracy $(d=0.27)$.

Overall, regarding fluency improvements, the results were in line with some other studies in the field. For example, Skehan (2009) found that as complexity improves, so does fluency. In this study, too, a trade-off was detected between form (complexity, accuracy) and fluency, and between complexity and accuracy. However, the same findings were not congruent with Vercellotti's (2015) research. In her research, after receiving the treatment, all CAF components improved in a linear fashion and no trade-off was observed among them. Nevertheless, she also reported a linear relationship between complexity and fluency. Our findings were also in line with studies by Thai and Boers (2015) and De Jong (2012), who showed the positive effects of 4/3/2 activities on fluency. In terms of improvement regarding SRA and SRB, our findings were in line with that of Li et al.'s (2015). They concluded that in the case of pre-task planning time -another speaking technique used in the treatment- MLR and SRB improved while SRA did not. The same findings were in accordance with Yurong and Yin (2008) who found a correlational relationship between self-esteem, motivation, anxiety, personality type, and fluency. Nevertheless, it seems necessary to conduct more studies to support these findings, which points to the need for further research in this area.

\section{Conclusion}

The results of this study showed that students' self-image could determine their success, or lack thereof, when it comes to their English-speaking skills in that the EG students managed to incorporate within their realistic and healthy self-images the image of a successful language learner as well. Like most other studies, however, the present study is subject to several limitations that could restrict the generalizability of its findings. Firstly, the study was limited to the low-intermediate English proficiency level and factors such as the age and gender of the participants were not controlled. Secondly, the sample size was rather small and the sample was not randomly selected as the participants had signed up for the classes voluntarily. Despite these limitations, the 
findings can have valuable implications for the theory and practice of language teaching. From a theoretical point of view, the results of the present study supported the idea that self-image is dynamic and flexible and can be managed and improved by receiving proper psychological training and implementing appropriate techniques. From a practical point of view, on the other hand, the present findings provide evidence on the effects of self-image as a psychological factor affecting English learners' oral performance. These findings could draw the practitioners' attention to redesigning their teaching practices by taking into account the need for improving their learners' self-image. In this sense, this research is applicable especially to English speaking courses for a range of proficiency levels where the focus is on one or all CAF components. A second important practical implication of this study could be geared toward pre- and in-service teacher training courses where they can learn about the important role of self-image so that they could converge self-image improving techniques into their teaching approaches. As the third practical implication, the findings could also be beneficial to curriculum and syllabus designers, making them aware of the potential for incorporating these techniques into the design of curricula and syllabi in an attempt to achieve more satisfactory outcomes.

As the results of this study demonstrated the role self-image could play in the quality of low-intermediate Iranian learners' L2 oral performance, future studies could be designed to cover other oral proficiency levels, i.e. advanced, upper-intermediate, and beginner levels. Additional work is also required to determine whether this treatment could be as effective as it was here in the case of other language skills (reading, writing, and listening) or any of their subskills. Finally, future studies can examine the long-term effects of implementing self-image training techniques on the students' oral proficiency by administering delayed post-tests in addition to the immediate ones.

\section{Conflict of Interests}

The authors declare that they have no conflicts of interest.

\section{References}

Ahmadian, M. J., \& Tavakoli, M. (2011). The effects of simultaneous use of careful online planning and task repetition on accuracy, complexity, and fluency in EFL learners' oral production. Language Teaching Research, 15(1), 35-59. https://doi.org/10.1177/1362168811425433

Ahour, T., \& Hassanzadeh, Z. (2015). An investigation of the relation between self-esteem, indirect strategy use and Iranian intermediate EFL learners' oral language proficiency. Theory and Practice in Language Studies, 5(2), 442-451. https://doi.org/10.17507/TPLS.0502.28

Al Nakhalah, A. (2016). Problems and difficulties of speaking that encounter English language students at Al Quds Open University. International Journal of Humanities and Social Science Invention, 5(12), 96-101.

Alsadhan, R. O. (2011). Effect of textual enhancement and explicit rule presentation on the noticing and acquisition of L2 grammatical structures: A meta-analysis [Unpublished doctoral dissertation]. Colorado State University.

Ary, D., Jacobs, L. C., Sorensen Irvin, C. K., \& Walker, D. A. (2019). Introduction to research in education (10 ${ }^{\text {th }}$ ed.). Wadsworth, Cengage Learning.

Brown, A. (2003). Interviewer variation and the co-construction of speaking proficiency. Language Testing, 20(1), 1-25. https://doi.org/10.1191/02655322031t242oa

Brown, A., \& Hill, K. (2007). Interviewer style and candidate performance in the IELTS oral interview. In L. Taylor \& P. Falvey (Eds.), IELTS collected papers: Research in speaking and writing assessment (pp. 37-61). Cambridge University Press.

Cliffordson, C. (2004). Effects of practice and intellectual growth on performance on the Swedish Scholastic Aptitude Test (SweSAT). European Journal of Psychological Assessment, 20, 192-204. https://doi. org/10.1027/1015-5759.20.3.192

Cohen, J. (1988). Statistical power analysis for the behavioral sciences (2nd ed.). Erlbaum.

Crystal, D. (2003). English as a global language (2nd ed.). Cambridge University Press.

De Jong, N. H. (2012). Second language fluency: Speaking style or proficiency? Correcting measures of second language fluency for first language behavior. Applied Psycholinguistics, 36(2), 223-243. https://doi. 
org/10.1017/S0142716413000210

Delany, T. (2012). Quality and quantity of oral participation and English proficiency gains. Language Teaching Research, 16(4), 467 - 482. https://doi.org/10.1177/1362168812455586

Devi, S., \& Qiqiehi, S. (2016). The relationship between English language proficiency, academic achievement and self-esteem of non-native-English-speaking students. International Education Studies, 9(5), 147-155. https://doi.org/10.5539/IES.V9N5P147

Di Blasi, M., Cavani, P., Pavia, L., Baido, R., Grutta, S., \& Schimmenti, A. (2015). The relationship between self-image and social anxiety in adolescence. Child and Adolescent Mental Health, 20(2), 74-80. https://doi. org/10.1111/camh.12071

Ellis, R. (2008). The study of second language acquisition (2nd ed.). Oxford University Press.

Ellis, R., \& Barkhuizen, G. (2005). Analyzing learner language. Oxford.

Foster, F., \& Skehan, P. (1996). The influence of planning and task type on second language performance. Studies in Second Language Acquisition, 18(3), 299-323. https://doi.org/10.1075/tblt.1.16the

Geranpayeh, A. (2003). A quick review of the English quick placement test. Research Notes, 12(3), 8-10.

Geving, A. M., Webb, S., \& Davis, B. (2005). Opportunities for repeat testing: Practice doesn't always make perfect. Applied H.R.M. Research, 10, 47-56. https://doi.org/10.1037/e518612013-432

Glazier, T. F. (1998). Improving the poor self-image of the remedial student. Paper presented at the Conference on College Composition and Communication, Denver, the United States.

Gurler, I. (2015). Correlation between self-confidence and speaking skill of English language teaching and English language and literature preparatory students. Current Research Journal of Social Sciences, 1(2), 14-19.

Haidara, Y. (2014). Psychological factors affecting English speaking performance for the English learners in Indonesia. Universal Journal of Educational Research, 4(7), 1501-1505. https://doi.org /10.13189/ ujer.2016.040701

Hausknecht, J. P., Halpert, J. A., Di Paolo, N. T., \& Gerrard, M. O. (2007). Retesting in selection: A meta-analysis of coaching and practice effects for tests of cognitive ability. Journal of Applied Psychology, 92, 373-385. https:// doi.org /10.1037/0021-9010.92.2.373

Hintikka, U., Marttunen, M., Pelkonen, M., Laukkanen, L., Viinamaki, H., \& Lehtonen. J. (2006). Improvement in cognitive and psychosocial functioning and self-image among adolescent patients with suicide attempts. BMC Psychiatry, 30(1), 1-10. https://doi.org /10.1186/1471-244X-6-58

Hirsch, C. R., Meynen, T., \& Clark, D. M. (2004). Negative self-imagery in social anxiety contaminates social interactions. Memory, 14(2), 496-506. https://doi.org /10.1080/09658210444000106

Housen, A., \& Kuiken, F. (2009). Complexity, accuracy, and fluency in second language acquisition. Applied Linguistics, 30(4), 461-473. https://doi.org/10.1093/applin/amp048

Ihsan, M. (2016). Students' motivation in speaking English. Journal of English Educators Society, 1(1), 31-48. https://doi.org/10.11648/j.ijla.20190706.18

Iwashita, N. (2010). Features of oral proficiency in task performance by EFL and JFL learners. In Prior, T., Watanabe, Y. \& Lee, S. (Eds.), Selected proceedings of the 2008 second language research forum: Exploring SLA perspectives, positions, and practices (pp. 32-47). Cascadilla Proceedings Project.

Juhana, J. (2012). Psychological factors that hinder students from speaking in English class (a case study in a senior high school in south Tangerang, Banten, Indonesia). Journal of Education and Practice, 3(12), 100-110.

Khatib, F., \& Maarof, N. (2015). Self-efficacy perception of oral communication ability among English as a second language (ESL) technical students. Procedia - Social and Behavioral Sciences, 204, 98-104. https://doi. org/ 10.1016/j.sbspro.2015.08.121

Knapp, K. (2015). English as an international lingua franca and the teaching of intercultural communication. Journal of English as a Lingua Franca, 4(1), 173-189. https://doi.org/10.1515/jelf-2015-0003

Koosha, B., Ketabi, S., \& Kassaian, Z. (2011). The effects of self-esteem, age and gender on the speaking skills of intermediate university EFL learners. Theory and Practice in Language Studies, 1(10), 1328-1337. http://dx.doi. org/10.17507/tpls.0601.09

Lee, K. R., \& Oxford, R. (2007). Differences in strategy use, language attitudes, and self-image between Korean vocational students and traditional students. English Language Teaching, 19(1), 1-28. https://doi.org/10.17936/ pkelt.2007.19.1.001

Lee, S., \& Huang, H. (2008). Visual input enhancement and grammar learning: A meta-analytic review. Studies in Second Language Acquisition, 30, 307-331. https://doi.org/10.1017/S0272263108080479

Li, L., Chen, J., \& Sun, L. (2015). The effects of different lengths of pre-task planning time on L2 learners' oral test performance. TESOL Quarterly, 49(1), 38-66. https://doi.org/10.1002/tesq.159

Lievens, F., Buyse, T., \& Sackett, P. R. (2005). Retest effects in operational selection settings: Development and 
test of a framework. Personnel Psychology, 58, 981-1007. https://doi.org/10.1111/j.1744-6570.2005.00713.x Lipsey, M. W. (2009). Identifying interesting variables and analysis opportunities. In H. Cooper, L. V. Hedges, \& J. C. Valentine (Eds.), The handbook of research synthesis (2nd ed., pp. 147-158). Russell Sage Foundation.

Liu, M. (2013). English Bar as a venue to boost students' speaking self-efficacy at the tertiary level. English Language Teaching, 6(12), 27-37. https://doi.org/10.5539/ELT.V6N12P27

Mai, L. T. (2011). An investigation into factors that hinder the participation of university students in English speaking lessons [Unpublished master's thesis]. University of Languages and International Studies. repositories.vnu. edu.vn/jspui/bitstream/123456789/42495/1/04051000606.pdf

Maltz, M. (1960). Psycho-Cybernetics: A new way to get more living out of life. Prentice Hall Press.

Maltz, M. (1999). Zero resistance living: The Pscycho-Cybernetics mastery series. Prentice Hall Press.

Malvern, D., \& Richards, B. (2002). Investigating accommodation in language proficiency interviews using a new measure of lexical diversity. Language Testing, 19(1), 85-104. https://doi.org/10.1191/0265532202lt221oa

McKee, G., Malvern, D., \& Richards, B. (2000). Measuring vocabulary diversity using dedicated software. Literary and Linguistic Computing, 15(3), 323-337. https://doi.org/10.1093/llc/15.3.323

Mcleod, B., Southam-Gerow, M., Jenson-Doss, A., Hogue, A., Kendall, P., \& Weisz, J. (2017). Benchmarking treatment adherence and therapeutic competence in individual cognitive-behavioral treatment for youth anxiety disorders. Journal of Clinical Child and Adolescence Psychology, 48(1), 1-13. https://doi.org/10.1080/1 5374416.2017.1381914

McMullen, T. (2013). Self-image. In Encyclopedia of behavioral medicine (vol. 2, pp. 1744-1745). Springer.

Meihua, L. (2012). Predicting effects of personality traits, self-esteem, language class risk-taking and sociability on Chinese university EFL learners' performance in English. Journal of Second Language Teaching and Research, 1(1), 30-57. https://doi.org/10.5420/JSLTR.01.01.3318

Meisel, J. M., Clahsen, H., \& Pienemann, M. (1981). On determining developmental stages in natural second language acquisition. Studies in Second Language Acquisition, 3(2), 109-135. https://doi.org/10.1017/ S0272263100004137

Nakatsuhara, F. (2008). Inter-interviewer variation in oral interview tests. ELT Journal, 62(3), 266-275. https:// doi.org/10.1093/elt/ccm044

Norris, J. M. (2012). Meta-analysis. In C. Chapelle (Ed.), Encyclopedia of Applied Linguistics (pp. 3653-3662). Malden, MA: Wiley.

Norris, J. M., \& Ortega, L. (2009). Towards an organic approach to investigating CAF in instructed SLA: The case of complexity. Applied Linguistics, 30(4), 555-578. https://doi.org/10.1093/applin/amp044

Norton, B., \& Toohey, K. (2001). Changing perspectives on good language learners. TESOL Quarterly, 35(2), 307322. https://doi.org/10.2307/3587650

Offer, D., Ostrov, E., Howard, K., \& Atkinson, R. (1988). The teenage world. Springer Science.

Omaggio, A. (1986). Teaching language in context: Proficiency-oriented instruction. Heinle \& Heinle.

Ostovar, A., Safaee, E., \& Sobhanifar, A. (2015). The effect of shyness on English speaking scores of Iranian EFL learners. Journal of Literature, Languages and Linguistics, 12, 22-28.

Park, H., \& Lee, A. R. (2005). L2 learners' anxiety, self-confidence and oral performance. Paper presented at the Pan-Pacific Association of Applied Linguistics (PAAL), Japan.

Plonsky, L., \& Oswald, F. L. (2014). How big is "big"? Interpreting effect sizes in L2 research. Language Learning, 64(4), 878-912. https://doi.org/10.1111/lang.12079

Proctor, B. (2002). The winner's image. Arizona, AZ: Life Success Productions.

Richard, J. (2008). Teaching listening and speaking: From theory to practice. Cambridge University Press.

Ryum, T., Vogel, p., Walderhaug, E., \& Stiles, T. (2015). The role of self-image as a predictor of psychotherapy outcome. Scandinavian Journal of Psychology, 56(1), 62-8. https://doi.org/10.1111/sjop.12167

Sandi-Urena, S., \& Gatlin, T. (2013). Factors contributing to the development of graduate teaching assistant self-image. Journal of Chemical Education, 90(10), 1303-1309. https://doi.org/10.1021/ed200859e

Sato, K., (2003). Improving our students' speaking skills: Using selective error correction and group work to reduce anxiety and encourage real communication. Akita Prefectural.

Skehan, P. (2009). Modelling second language performance: Integrating complexity, accuracy, fluency, lexis. Applied Linguistics, 30(4), 510-532. https://doi.org/10.1093/APPLIN/AMP047

Skehan, P., \& Foster, P. (2005). Strategic and on-line planning: The influence of surprise information and task time on second language performance. In R. Ellis (Ed.), Planning and task performance in a second language (pp. 195-216). John Benjamins.

Sopis, J. (1965). The relationship of self-image of a reader to reading achievement. Intervention in School and Clinic, 1(2), 94-113. https://doi.org/10.1177/105345126500100209 
Stevens, J. (2009). Applied multivariate statistics for the social sciences. Erlbaum.

Thai, C., \& Boers, F. (2015). Repeating monologue under increasing time pressure: Effects on fluency, complexity and accuracy. TESOL Quarterly, 50(2), 1-25. https://doi.org/10.1002/tesq.232

Yurong, Z., \& Yin, N. (2008). The effects of affective factors on oral English fluency of college English students. Christian English Language Educators Association, 31(2), 107-116. http://dx.doi.org/10.7575/aiac. ijalel.v.5n.3p.133

Vacha-Haase, T., \& Thompson, B. (2004). How to estimate and interpret various effect sizes. Journal of Counseling Psychology, 51,473-481. https://doi.org/10.1037/0022-0167.51.4.473

Vercellotti, M. (2015). The development of complexity, accuracy and fluency in second language performance: A longitudinal study. Applied linguistics, 38(1), 1-23. https://doi.org/10.1558/cj.29513

Waltz, J., Addis, M., Koerner, K., \& Jacobson, N. (1993). Testing the integrity of a psychotherapy protocol: Assessment of adherence and competence. Journal of Counselling and Clinical Psychology, 61(4), 620-630. https://doi.org/10.1037//0022-006x.61.4.620.

Woodrow, L. (2006). Anxiety and speaking English as a second language. Regional Language Centre, 37(3), 308328. https://doi.org/10.1177/0033688206071315

Zeinivand, T., Azizifar, A., \& Gowhary, H. (2015). The relationship between attitude and speaking proficiency of Iranian EFL learners: The case of Darrehshehr city. Procedia Social and Behavioral Sciences, 199, 240-247. https://doi.org/10.1016/j.sbspro.2015.07.512 


\section{APPENDIX A}

\section{IELTS Speaking Test 1 (Pre-test)}

\section{PART 1}

The examiner asks the candidate about him/herself, his/her home, work or studies and other familiar topics.

\section{EXAMPLE}

\section{Friends}

- How often do you go out with friends? [Why, Why not?]

- Tell me about your best friend at school.

- How friendly are you with your neighbors? [Why, Why not?]

- Which is more important to you, friends or family? [Why?]

\section{PART 2}

(You will have to talk about the topic for one to two minutes. You have one minute to think about what you are going to say. You can make some notes to help you if you wish.)

Describe a writer you would like to meet.

- You should say:

- Who the writer is

- What you know about this writer already

- What you would like to find out about him/her

- And explain why you would like to meet this writer

\section{PART 3}

\section{Discussion topics:}

\section{Reading and children}

\section{Example questions:}

What kinds of book are most popular with children in your country? Why do you think that is? Why do you think some children do not read books very often?

How do you think children can be encouraged to read more?

\section{Reading for different purposes:}

Example questions:

Are there any occasions when reading at speed is a useful skill to have? What are they? Are there any jobs where people need to read a lot? What are they?

Do you think that reading novels is more interesting than reading factual books? Why is that? 


\section{APPENDIX A}

\section{IELTS Speaking Test 2 (Post-test)}

\section{PART 1}

The examiner asks the candidate about him/herself, his/her home, work or studies and other familiar topics.

\section{EXAMPLE}

\section{Photographs}

- What type of photos do you like taking? [Why, Why not?]

- What do you do with the photos you take? [Why, Why not?]

- When you visit other places, do you take photos or buy postcards? [Why, Why not?]

- Do you like people taking photos of you? [Why, Why not?]

\section{PART 2}

(You will have to talk about the topic for one to two minutes. You have one minute to think about what you are going to say. You can make some notes to help you if you wish.)

Describe a day when you thought the weather was perfect.

You should say:

- Where you were on this day

- What the weather was like on this day

- What you did during the day

- And explain why you thought the weather was perfect during this day.

\section{PART 3}

\section{Discussion topics:}

\section{Types of weather}

Example questions:

What type of weather do people in your country dislike most? Why is that?

What jobs can be affected by different weather conditions? Why?

Are there any important festivals in your country that celebrate a season or a type of weather?

\section{Weather forecasts}

Example questions:

How important do you think it is for everyone to check what the next day's weather will be? Why? What is the best way to get accurate information about the weather?

How easy or difficult it is to predict the weather in your country? Why is that? 


\section{APPENDIX B}

\section{Self-image Improvement Worksheet}

\section{A sample of Lesson 1}

\section{LESSON ONE}

\section{The power of imagination}

Napoleon Bonaparte once wrote, "the human race is governed by its imagination." Unfortunately for many people, imagination is not good government. It is a dictatorship, an instrument of failure. By not using their imaginations positively, creatively, they are enslaved by allowing their imagination to run wild, without control, to conjure up images more or less at random. These people inevitably suffer from a self-image of failure, and are incapable of reaching their goals.

We are all well aware of the fact that behavior is controlled by the mind, the brain. The brain tells us what to do in the future based on its knowledge of the past. The brain has no future reading or fortunetelling capabilities. It is a marvelous computer, but it is limited to the past and present. The only way it can see into the future is through the imagination.

You have total control over your imagination. You can imagine any way you want to in the future, success or failure. It's all up to you. But all too often, people are not willing to exercise this control. They allow their imagination to destroy their potential by picturing situations from the past in which they have failed. We all carry mental scrapbooks, but instead of preserving the joyous occasions of life, the moments of accomplishments, some people save only their times of failure and frustration.

But it is so easy and simple to take control over your imagination. All you have to remember is that the brain has a hard time distinguishing between real and imagined experiences, if they are portrayed vividly enough.

If we picture ourselves functioning in specific situations, it is nearly the same as actual performance. Mental practice can help you perform better in real life.

\section{OVERVIEW}

In this lesson, you will begin to develop three of the major tools of Psycho-Cybernetics that you will use to change your life. They are:

1. Using your imagination creatively

2. Setting clear, specific, and realistic goals

3. Learning to relax your body and mind

Research has demonstrated that the exercises and activities in this program are most effective when done in a relaxed playful state of mind- a childlike sense of openness and curiosity in the mental attitude most conducive to learning.

Do the exercises in the order in which they appear. Try to allow yourself 30 to 45 minutes uninterrupted quiet time at the end of each day to practice. Do only as much each day as feels comfortable to you. Remember: don't strain. Your Psycho-Cybernetics program is meant to be enjoyed as well as studied.

(For further information read Chapter Three, Imagination- The First Key TO Your Success Mechanism in the Psycho-Cybernetics book).

\section{Principles of Spiritual and Psychological Relaxation}

Here are four principles of spiritual and psychological relaxation. Being able to live these principles means being able to live a creative and rewarding life, free of negative influences that hold us back. Keep these principles in mind as you progress through this course. You will notice how much easier they become as you acquire more skills in the practice of Psycho-Cybernetics. 
1 Forgive others.

2 Forgive yourself.

3 See yourself at your best.
No strings attached. No sense of condemnation, no forgiveness on the installment plan. A clean slate.

You are only human. Accept yourself with kind eyes.

A person of confidence, not at your worst, a person of frustration.

4 Keep up with yourself always, never with someone else. Stop criticizing others.

\section{Self-inventory worksheet}

An important tool in changing your self-image to one that expresses your productive and success-oriented self is to have an accurate, up-to-date list of your good qualities and negative qualities. In the special list below write the good things about yourself as well as the things that you think could be improved.

For example, under assets, you might list qualities such as kind, hardworking, punctual, etc. Write them down no matter how small you think they are.

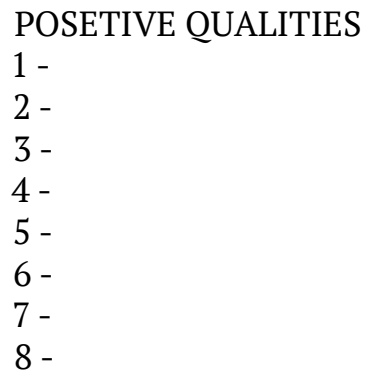

\section{ONCE IMPOSSIBLE-NOW EASY}

Think of three things you were sure at one time you wouldn't be able to learn that now are easy for you. (For example, tying your shoes, riding a bike, driving a stick-shift car, reading) $1-$

$2-$

$3-$

(Remember how difficult they once seemed and how easy they are now.)

Now think of at least three things that you would like to be able to do in the future that seem difficult or impossible to you now. (Be sure they are realistic. For example, learning the piano is realistic, but playing a concert at Carnegie Hall next year is not.)

$1-$

2 -

3 - 
This exercise is to have you realize that you have already accomplished goals in your life you once saw as difficult if not impossible. You can use the confidence of your past successes to help you reach your goals in the present and the future.

\section{An identical world}

Imagine the world where everybody is exactly the same. The same looks, age, skills, goals, everything. What would such a world look like, sound like, feel like? Write down your observations briefly. Remember there is no «right» answer.

What does this vision make you think about your unique individuality?

\section{Once impossible-now easy}

Memorize this simple phrase: ONCE IMPOSSIBLE-NOW EASY, and use it as your personal slogan, your description of your entire life experience.

Whenever you are confronted with a particularly hard or challenging situation, a new skill you need to learn that seems intimidating or difficult:

1. STOP- do NOT let anxiety and stress build up!

2. Go to the Quiet Room in your mind and...

3. Quickly remember the list of ALL the things that in your entire life were "ONCE IMPOSSIBLE" but are "NOW EASY".

4. SEE that you have lived this transition time and time and time and time again

5. Tell your Servo-Mechanism "here is another one".

6. ... and what seems "impossible" would soon be «easy». 